\section{Compatible with all systems}

Digital Imaging and Communications in Medicine (DICOM) is an international standard for creating, transmitting, processing and storing digital images. Durr Dental hardware and software is compatible with all systems sup-

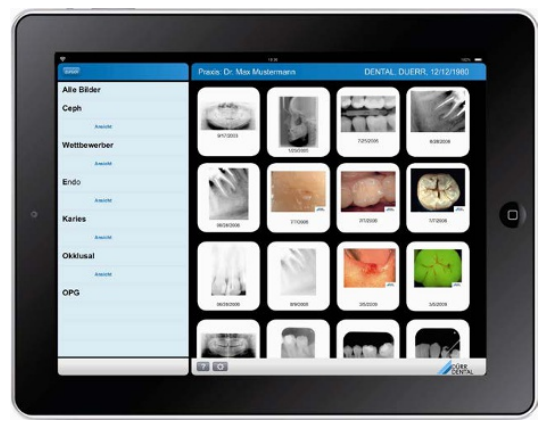
porting DICOM. There are many advantages to practices in terms of time saved and reduced costs, as well as the obvious quality implications of standardising documentation.

Technology pervades practice life and will continue to do so, which is why Durr Dental continually develops its imaging software in response to both the growing clinical demands of surgeries and the increasing technological capabilities. Durr's imaging iPad app, for example, is ideal for calling up patient records and includes free-hand sketches and a demo database of sample images to assist you with patient communication. You can also use the database offline, and it's compatible with all common practice management programmes.

To find out more contact your dental dealer or call Durr Dental directly on 01536526740 .

\section{Implantology meeting}

Registration is now open for Nobel Biocare's Dublin Team Conference 2016.

Held on 11 November at the Westin Dublin Hotel, it will be an unmissable event for all team members involved in dental implantology.

The exceptional speaker line-up consists of world-renowned professionals from across the globe, including Professor Hannes Wachtel, Saj Jivraj and Steve Bongard. Overseeing the programme will be our highly celebrated Scientific Co-Chairs Paul O'Reilly and David Harris.

\section{Adhesive with integrated desensitisation}

Adhese Universal is a single component light-cured adhesive for direct and indirect bonding procedures. Adhese Universal is compatible with all etching techniques. An integrated desensitising effect prevents fluid movement in the dentine tubules and thus minimises the risk of postoperative sensitivity.

Wetting and infiltration of dentine tubules under moist and wet conditions occurs by contact with the hydrophilic solvents and methacrylate monomers contained in the adhesive. In addition, the acidic compounds in the dentine precipitate as insoluble calcium salts, facilitating the mechanical blocking and sealing of the dentine tubules. This integrated 'desensitising effect' prevents fluid movement in the dentine tubules and minimises the risk of microleakage and postoperative sensitivity.

Adhese Universal provides effective mechanical blocking and sealing of the dentine tubules under dry and wet conditions. It results in a homogeneous adhesive film with defined resin tags that reliably seal the dentine. Fluid movement in the tubules and thus postoperative sensitivity associated with that movement are prevented.

http://www. ivoclarvivadent. us/en-us/productcategories/bond/ adhese-universal

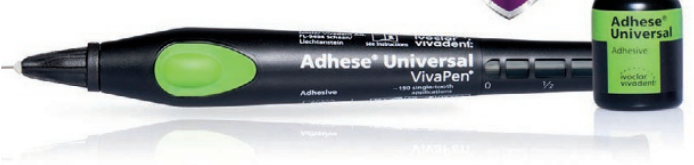

An array of relevant topics will be covered, offering a wealth of information and inspiration for every member of the dental team to improve their workflow and enhance the patient experience.

What's more, you will be able to find out more about our latest innovations and how we can help you treat more patients better.

Don't miss Nobel Biocare's Dublin Team Conference 2016! with the theme 'Improving patients' quality of life: Osseointegration reimagined'.

For more information or to book your place, call 02087563300 or email education.uk@nobelbiocare.com.

\title{
The first CT scanning services for impressions
}

NimroDENTAL are proud to introduce the first computerised tomography (CT) scanning services for impressions in the UK. NimroDENTAL are now one of the only European orthodontic labs with a CT scanner, the most accurate way to transfer impressions into models.

- CT scanners have the ability to record any undercut, which may be missed by a surface scanner scanning plaster models (like deep interdental areas); a higher level of accuracy and highly precise treatment plans can be guaranteed

- When attempting to release cast plaster models from impressions with deep undercuts, a tooth on the model may break and tear meaning a second cast may be inaccurate. A CT scan will eliminate this problem

- When removed from a casted model, some impressions with very tight interdental surfaces cause thin material to tear away which inhibits the full anatomy of the teeth to be scanned
- Eliminating plaster casting is better for the environment as there is no risk of toxic hydro-sulphate being released into the drainage system.

Once the impressions are scanned and translated into 3D models NimroDENTAL print them on a 3 printer and the files are emailed to you and are free to download. www.nimrodental.com
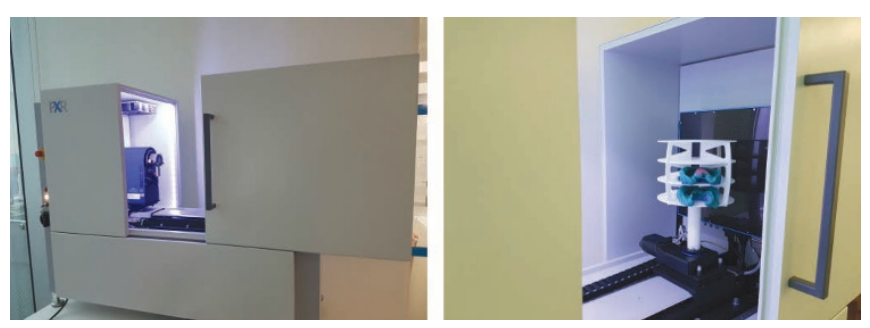